\title{
Association between interleukin 8 receptor $\alpha$ gene (CXCR1) and mastitis in dairy cattle
}

\author{
ADRIANNA PAWLIKI, GRAŻYNA SENDER ${ }^{l}$ MAGDALENA KAPERA², \\ AGNIESZKA KORWIN-KOSSAKOWSKA ${ }^{l}$ \\ ${ }^{1}$ Institute of Genetics and Animal Breeding of the Polish Academy of Sciences, Jastrzebiec, Magdalenka, Poland \\ ${ }^{2}$ Student at Wroclaw University of Environmental and Life Sciences, Wroclaw, Poland
}

\begin{abstract}
The innate immune response plays an important role in the course of bacterial infections. Innate immunity effectiveness relies on the expression of many genes, connected, among others, to the activity of neutrophils. Interleukin $8(I L-8)$ receptor $\alpha$, coded by the CXCR1 gene, is present on the neutrophil surface and binds pro-inflammatory IL-8 with high affinity. This is why the bovine CXCR1 gene carries a potential for use as a dairy cattle mastitis marker. To date, several studies on the CXCR1 polymorphism brought out contradictory results. The aim of this study was to analyse the association between two SNPs of the CXCR1 gene, which is potentially important for the protein function and animal phenotype for mastitis susceptibility. A total of 554 Polish Holsteins were genotyped, and 140 among them were bacteriologically tested. The differences between animals carrying different genotypes and haplotypes of CXCR1 in test day somatic cell count (SCC) and Staphylococcus aureus mastitis susceptibility were estimated. We found that test day SCC was significantly related to CXCR1+472 SNP but not to CXCR1+735 SNP. No statistically significant association between CXCR1 polymorphism and susceptibility to $S$. aureus mastitis was found in the studied herd.
\end{abstract}

Key words: mastitis, S. aureus, bovine CXCR1, somatic cell count.

(Centr Eur J Immunol 2015; 40 (2): 153-158)

\section{Introduction}

Staphylococcus aureus (S. aureus) is a predominant aetiological agent in both subclinical and clinical forms of udder inflammations. Infections and inflammations caused by $S$. aureus - the major mastitis pathogen - are the most difficult to treat and control $[1,2]$. The innate immune response plays an unquestionable role in the course of bacterial infections [3]. During mastitis, caused by S. aureus, an early response to the pathogen is crucial to overcome the disease [4]. The effectiveness of innate immunity depends on the expression of many genes, connected, among others, to the activity of neutrophils [3, 5]. Interleukin 8 (IL-8) receptor $\alpha$ (IL8RA), coded by the $C X C R 1$ gene, is present on the neutrophil surface and binds pro-inflammatory IL-8 with high affinity. Interleukin 8 expression in mammary tissue increases during S. aureus infection [2]. Many authors have highlighted the importance of IL8RA during the first hours after the infection. Genetic polymorphism of $C X C R 1$ has been proven to affect disease susceptibility in humans [6]. Regarding dairy cows, one can suspect that IL8RA is especially important during $S$. aureus mastitis due to the "immunosuppressive nature" of the infection [7]. The $C X C R 1$ gene has been regarded as a potential marker of dairy cows' mastitis for about 10 years now, since Youngerman et al. in 2004 [8] found that the GG variant of $C X C R 1$ polymorphism, occurring in the +735 position of the gene, is connected to a lower prevalence of subclinical mastitis. To date, dozens of SNPs have been found in CXCR1 coding and regulatory regions [8-10]; few of them belong to the non-synonymous mutations group; however, the majority of them do not influence the amino acid content of the protein. The results from several authors are often contradictory and do not reveal any particular connection between $C X C R 1$ variants and mastitis resistance besides a clear suggestion that $C X C R 1$ alleles from different SNPs form more or less common haplotypes. There was a suggestion by Goertz et al. [11] that CXCR1 SNPs can serve as mastitis markers only in particular populations.

One of the SNPs chosen for the current study was previously analysed by several authors. Initially, this SNP was localised at the +777 position in the CXCR2 gene [8, $12,13]$, and later it was correctly annotated to the $C X C R I$ +735 position $(C X C R 1+735)$ [14]. This missense polymorphism (G/C) causes a change (245: glutamine to histidine) in the important part of the IL8RA amino acid chain:

Correspondence: Prof. Grażyna Sender, Institute of Genetics and Animal Breeding of the Polish Academy of Sciences, Jastrzębiec, 05-552 Magdalenka, Poland, tel. +48 2273671 27, fax +48 2275614 17, e-mail: g.sender@ighz.pl 
$C X C R 1+735 \mathrm{SNP}$ is localised within region coding for the third intracellular loop, responsible for calcium signalling and G-protein interaction [8].

Second SNP $(C X C R 1+472)$, localised at the +472 position of the $C X C R 1$ gene, was taken from the cattle genome browser (www.ensembl.org) and was not previously analysed in relation to mastitis. The occurrence of this $(\mathrm{A} / \mathrm{G})$ polymorphism results in valine to alanine substitution. $C X C R 1+472$ was chosen for the current analysis due to its probable role for the protein (http://www.ensembl.org/ Bos_taurus/Variation/Mappings?db=core;g=ENSBTAG0 0000026753;r=2:106936887106940905; source $=\mathrm{dbSNP}$; $\mathrm{t}=$ ENSBTAT00000038197; $=$ rs2 11042414 ; $\mathrm{vdb}=$ variation; $\mathrm{vf}=13925220$ ).

In the corresponding human IL8RA fragment, SNP +472 is localised in the transmembrane section of the protein [15]; in silico analysis done by the authors (results not shown) suggest that in bovine IL8RA the place of CXCR1+472 SNP is similar. In his PhD thesis, Russell in 2012 [16] presented an IL8RA sequence, in which +472 SNP is localised only two amino acids from the extracellular section of the protein, which suggests that +472 SNP may impact the interaction between IL-8 and IL8RA. The exact physiological meaning of the fragment, in which SNP is localised, is unknown.

The aim of the study was to analyse associations between $C X C R 1+472$ and $C X C R 1+735$ SNPs and subclinical mastitis susceptibility, with particular attention paid to $S$. aureus mastitis. This pathogen was chosen as it poses a serious threat to Polish dairy herds.

\section{Material and methods}

\section{Animals}

The material for this study consisted of 554 Polish Holstein dairy cows. The animals belonged to one herd. Performance data were scored in an official Polish milk recording system. Milk samples for somatic cell count (SCC), blood samples for genotype determination, and performance data were collected between 2001 and 2014 from all cows. Milk samples for bacteriological examinations were collected between 2012 and 2013 from 140 animals.

\section{Molecular analysis}

$C X C R 1+472$ and $C X C R 1+735$ genotypes were determined for 552 and 554 cows, respectively. For DNA extraction we used samples of blood collected before the start of the experiment, which allowed us to determine the genotypes for the cows present in the studied herd from the year 2001. The method, invented by Kanai et al. in 1994 [17], was used to extract DNA from blood obtained from the tail vein. Two separate PCR protocols were designed for each SNP. Primers for amplification of the DNA fragments were designed using Primer3 software (http:// frodo.wi.mit.edu/), and their sequences were as follows: $C X C R 1+735$ fwd: AGCAGAGCAGGAAGACGAG, rev: GTGCCAGAACAAAGGTGAC; $C X C R 1+472 \mathrm{fwd}$ : TTATCATCCGCCATTTCGTT, rev: TATGCCCTGGTCTTCTTGCT. Amplification reaction protocol was designed as follows: initial denaturation at $94^{\circ} \mathrm{C}$ for 3 minutes, followed by 37 cycles of: DNA denaturation at $94^{\circ} \mathrm{C}$ for 1 minute, annealing at $50^{\circ} \mathrm{C}(C X C R 1+735)$ or at $58^{\circ} \mathrm{C}(C X C R 1+472)$ for 50 seconds, and elongation in $74^{\circ} \mathrm{C}$ for 1 minute. The final elongation lasted for 7 minutes at $74^{\circ} \mathrm{C}$. Restriction enzymes were chosen using Webcutter software (http://rna.lundberg.gu.se/cutter2/). Restriction Fragments Length Polymorphism (RFLP) reaction was done with the use of Fermentas TM (Thermo Scientific Waltham, MA, USA) nucleases according to the manufacturer's recommendations (CXCR1+735: BaeGI, $C X C R 1+472$ : $B s a \mathrm{I})$. Agarose gel electrophoresis was conducted after the enzymatic digestion. DNA band patterns of the genotypes were: $C X C R 1+735: \mathrm{GG}-181 \mathrm{bp}$ band, $\mathrm{CG}-181+130+51$ bp bands; $C X C R 1+472: \mathrm{GG}-469$ bp band, AA $-269+200$ bp bands, AG $-469+269+200$ bp bands.

\section{Bacterial examination}

Milk samples for bacterial examination were obtained from 140 cows. These animals were present in the studied herd in 2012 and 2013, as historical milk samples were not available. Clinically infected cows were excluded from the analysis. Bacterial examinations were repeated at least three times during lactation.

Milk samples for bacteriological tests were taken from cleaned and dried teats, sanitised with $70 \%$ ethanol. Samples $(1 \mu \mathrm{l})$ were inoculated with Trypticase Soy Agar supplemented with sheep blood (5\%) (Graso, Starogard Gdanski, Poland). Plates were placed in $37^{\circ} \mathrm{C}$ for 3 days, and bacterial growth records were done after 24, 48, and 72 hours. Bacteria were identified due to the colony morphology, haemolysis, gram staining, catalase activity, and coagulase tube test. Cows were classified into one of three groups according identified bacteria: 1) S. aureus; 2) other mastitis pathogens; or 3) milk negative for the presence of mastitis pathogens. Cows classified as "negative" had all four quarters free from mastitis pathogens and low SCC $\left(<100000 \mathrm{SCC} * \mathrm{ml}^{-1}\right.$ of quarter milk) during all of their lactation. Cows classified as "S. aureus mastitis" had S. aureus isolated from at least one of the four quarters and high SCC (> $100000 \mathrm{SCC}^{*} \mathrm{ml}^{-1}$ of quarter milk) at least once during lactation. Cows classified as "other mastitis pathogens" had at least five colonies of potential mastitis pathogens (other than $S$. aureus, mostly CNS [coagulase negative staphylococci], environmental streptococci, and fungi) isolated from at least one quarter along with high SCC, at least once during lactation. Numbers of cows in- 
Table 1. Numbers of animals infected with $S$. aureus, other mastitis pathogens, or negative for the presence of mastitis pathogens in relation to the $C X C R 1$ genotype

\begin{tabular}{lccccc}
\hline CXCR1 SNP & Genotype & $\Sigma$ & S. aureus & Other pathogens & Negative \\
\hline+735 & CC & 1 & 0 & 1 & 0 \\
\cline { 2 - 6 } & GC & 97 & 49 & 34 & 14 \\
\cline { 2 - 6 } & GG & 42 & 19 & 15 & 12 \\
\hline+472 & AA & 31 & 14 & 24 & 5 \\
\cline { 2 - 6 } & AG & 68 & 18 & 13 & 8 \\
\hline
\end{tabular}

fected with $S$. aureus, other mastitis pathogens and negative for mastitis pathogens is given in Table 1.

\section{Statistical analysis}

\section{Association between the CXCR1 genotype and somatic cell count}

The association between the CXCRl genotype and SCC was determined using analysis of variance. The classification used for the analysis included the fixed effects of the $C X C R 1$ genotype, animal nested in $C X C R 1$ genotype, fixed effect of the year $\times$ season of testing interaction, year $\times$ season of calving, parity, and linear regressions on days in milk and on milk yield. Additionally, the GLM model included an occurrence of chronic mastitis in each lactation. Due to the low number of animals in $5^{\text {th }}$ to $8^{\text {th }}$ lactation, these parities were enclosed to the $5^{\text {th }}$ lactation. Differences between animals carrying a particular CXCR1 genotype were tested for significance with the Tukey range test using the GLM procedure (SAS ${ }^{\circledast}$ Software, SAS Institute Inc, Campus Drive Cary, NC 27513-2414, USA). The same model was used for the estimation of the effect of CXCR1 gene haplotypes upon test day SCC. Somatic cell count was logarithmically transformed (natural logarithm) due to the lack of a normal distribution of the trait [18].

\section{Association between the CXCR1 genotype and $S$. aureus mastitis}

Differences between occurrence of $S$. aureus or mastitis caused by other pathogens in CXCRI genotype or haplotype groups of animals were analysed statistically using $\chi^{2}$ test using the FREQ procedure and Wilcoxon and Kruskal-Wallis tests using the NPAR1WAY procedure (nonparametric one way analysis of variance) (SAS ${ }^{\circledR}$ Software).

\section{Results}

Table 2 shows the frequency of genotypes of $C X C R 1$, and Table 3 shows $C X C R 1$ haplotypes frequencies. Only two cows carried $C C$ genotype of $C X C R 1+735 \mathrm{SNP}$. The most popular genotypes were heterozygotes for both SNPs and therefore of animals carrying the most popular haplo- type CGAG (CXCR1+735/+472). In the studied herd, cows did not carry CCGG haplotype and the second rarest haplotypes were CCAG and CCAA. They were not included in the statistical analysis due to the low number of animals (Table 3).

The association between $C X C R 1$ genotypes and test day SCC is shown in Table 4. Regarding $C X C R 1+735$, no statistically significant differences in SCC between genotypes were found. Regarding CXCR1+472 SNP, animals carrying the A allele (AA or AG genotype) tended to have higher test day SCC than G homozygous animals.

The results of testing differences in test day SCC between animals carrying different haplotypes of $C X C R 1$ are presented in Table 5. Cows carrying double heterozygous haplotype CGAG (+735/+472) had the highest test day

Table 2. Genotype frequencies for $C X C R 1$ SNP

\begin{tabular}{cccc}
\hline CXCR1 SNP & Genotype & $\begin{array}{c}\text { Number } \\
\text { of animals }\end{array}$ & Frequency (\%) \\
\hline \multirow{2}{*}{+735} & CC & 2 & 0.36 \\
\cline { 2 - 4 } & GC & 314 & 56.68 \\
\cline { 2 - 4 } & GG & 238 & 42.96 \\
\hline \multirow{2}{*}{+472} & AA & 121 & 21.92 \\
\cline { 2 - 4 } & AG & 291 & 52.72 \\
\cline { 2 - 4 } & GG & 140 & 25.36 \\
\hline
\end{tabular}

Table 3. Haplotype frequencies for $C X C R 1$ SNP

\begin{tabular}{ccc}
\hline $\begin{array}{c}\text { Haplotype } \\
\text { CXCRI(+735+472) }\end{array}$ & Number of animals & Frequency (\%) \\
\hline CCAG & 1 & 0.18 \\
\hline CCAA & 1 & 0.18 \\
\hline GCAA & 100 & 18.21 \\
\hline GCAG & 170 & 30.97 \\
\hline GCGG & 41 & 7.47 \\
\hline GGAA & 19 & 3.46 \\
\hline GGAG & 118 & 21.49 \\
\hline GGGG & 99 & 18.03 \\
\hline
\end{tabular}


Table 4. Test day least square (LS) means and standard error (SE) for somatic cell count (SCC) in milk of cows carrying different $C X C R 1$ genotypes

\begin{tabular}{cccc}
\hline CXCR1 SNP & Genotype & SCC (LS mean) & SE \\
\hline+735 & CC & 13.13 & 0.14 \\
\cline { 2 - 4 } & CG & 12.82 & 0.09 \\
\cline { 2 - 4 } & GG & 12.86 & 0.07 \\
\hline+472 & AA & $12.80 \mathrm{~A}$ & 0.08 \\
\cline { 2 - 4 } & AG & $12.82 \mathrm{~B}$ & 0.07 \\
\cline { 2 - 4 } & GG & $12.47 \mathrm{AB}$ & 0.11 \\
\hline
\end{tabular}

Means marked by the same upper-case letter differ at $p<0.01$; marked with the same lower-case letter differ at $p<0.05$

Table 5. Test day least square (LS) means and standard error (SE) for somatic cell count (SCC) in milk of cows carrying different $C X C R 1$ haplotypes

\begin{tabular}{|c|c|c|}
\hline $\begin{array}{c}\text { CXCR1 Haplotype } \\
(+735+472) \\
\end{array}$ & SCC (LS mean) & SE \\
\hline CGAA & 12.53 ABCDIJ & 0.11 \\
\hline CGAG & $12.67 \mathrm{AEK}$ & 0.07 \\
\hline CGGG & 11.80 BEFGH & 0.16 \\
\hline GGAA & 12.66 CDFI & 0.07 \\
\hline GGAG & $12.66 \mathrm{GJ}$ & 0.07 \\
\hline GGGG & $12.60 \mathrm{HK}$ & 0.25 \\
\hline
\end{tabular}

SCC. Haplotype CGGG was related to significant, low SCC, and it differed significantly $(p<0.01)$ from any other haplotype. CGAG $(+735+472)$ haplotype, carried by $31 \%$ of the cows, was associated with significant, high SCC.

The numbers of cows of cows infected with different pathogens in relation to the $C X C R 1$ genotype are shown in the Table 1. Among 140 cows analysed, bacteriological samples from 22 were negative for the mastitis pathogens growth, 68 were infected with $S$. aureus, and 50 were infected with other pathogens. Analysis of the influence of the CXCR1 genotype on the risk of subclinical mastitis caused by $S$. aureus or other pathogens did not reveal any significant differences.

\section{Discussion}

Polymorphisms that cause changes in the amino acid sequence of IL8RA have the potential to be used as natural markers of mastitis susceptibility in dairy cows. To date, the most attention has been paid to the $C X C R 1+735$ polymorphism, due to its probable role in IL8RA function. Rambeaud and Pighetti in 2005 [13] found that the occurrence of $C X C R 1+735$ CC genotype is connected to im- paired neutrophil recruitment, explaining the physiological mechanism for the genetic differences to mastitis susceptibility. In the studied herd, the highest SCC was connected rather to the $C X C R 1+753 \mathrm{C}$ allele than to the $\mathrm{G}$ allele, although differences between genotypes were insignificant. In our study this polymorphism did not affect test day SCC and $S$. aureus mastitis susceptibility. The $\mathrm{C}$ allele frequency in our population was relatively low $(28.73 \%)$. In other studies, CXCR1+735 C frequency spanned between $36 \%$ and $67 \%$ in Holsteins $[8,9,11,16,19]$. Only two cows among our 554 carried $C X C R 1+735 \mathrm{CC}$ genotype. This can mean that the deleterious $\mathrm{C}$ variant of $C X C R 1+735$ is being eliminated from the studied herd. One should bear in mind that low test day SCC is not necessarily connected to the decreased mastitis incidence. As mentioned earlier, the CC variant of $C X C R 1+735$ polymorphism is connected to the impaired neutrophil migration [13], and it might mean that the lower test day SCC in cows carrying this genotype is in fact connected to chronic mastitis due to the low number and/or impaired activity of neutrophils in somatic cells. Not all previous studies connected $\mathrm{C}$ allele of $C X C R 1+735$ with mastitis susceptibility. Galvăo et al. [20] found that cows with $C X C R 1+735 \mathrm{CC}$ or $\mathrm{CG}$ genotype have a lower rate of clinical mastitis (CM) incidence, compared with GG genotype, which is contrary to the results obtained by Youngerman et al. [8]. Others found no significant association between CM, SCC, or somatic cell score and CXCR1+735 genotype [11, 16, 21] or haplotype [19].

The second polymorphism analysed $(C X C R 1+472)$ was significantly associated with SCC. Cows carrying AA or AG genotype had higher test day SCC than GG cows, which denotes the unfavourable role of the A allele (valine variant). The haplotype GGAA (CXCR1+735/+472) was associated with the high test day SCC (12.66), although only 19 cows carried such a haplotype, so the relationship is not certain. The low number of GGAA carriers suggests that they are being eliminated via selection towards low SCC. Among the haplotypes that were more frequent in the studied group, cows with GGGG and CGAA haplotype had the lowest test day SCC. GGGG haplotype was connected with a lower test day SCC than the separate genotypes that formed it. It can be noticed that the preferable role of the $\mathrm{G}$ allele of $C X C R 1+472$ was enhanced when this SNP was analysed with $C X C R 1+735$. The latter may suggest that polymorphisms other than those being analysed are in linkage disequilibrium with $C X C R 1+472$. This seems to confirm the role of haplotypes of $C X C R 1$ and the opinion that $C X C R I$ gene polymorphism should be analysed regarding many SNPs at the same time. Nonetheless, we think that $C X C R 1+472$ should be further analysed as this polymorphism carries the potential to serve as a functional marker. Our study is only preliminary in character because it was done with use of test day SCC and not the estimated breeding values (EBV) of the cows. Using EBV, which will be the second step of our analysis, will give 
a better view on the genetic background of mastitis susceptibility.

We found a lack of significance of the association between CXCRI polymorphism and S. aureus mastitis occurrence. It should be noted that not many studies have previously analysed this topic. Rambeaud and Pighetti found in 2005 [13] that neutrophils isolated from blood of the cows carrying $C X C R 1+735 \mathrm{CC}$ genotype are less effective in reactive oxygen species production, compared to the $C X C R 1+735 \mathrm{GG}$ cows, which denotes the impaired activity of neutrophils. A harmed neutrophil migration pattern in cows carrying $C X C R 1+735 \mathrm{CC}$ genotype was observed also by Elliot [22]. The above-mentioned authors, however, did not observe differences in neutrophils' capability of killing $S$. aureus or $S$. uberis, or differences in the infection rate in relation to the $C X C R 1$ genotype. We did not observe any differences between the susceptibility to $S$. aureus mastitis among animals carrying different CXCR 1 genotypes or haplotypes. In her doctoral thesis Crisp [23] analysed $C X C R 1$ haplotypes containing, among five SNPs, +735 SNP. She did not find any relationship between carriers of different genotypes and clinical S. aureus mastitis, but found significant differences between some of the haplotypes and subclinical $S$. aureus mastitis susceptibility. In her study, the $C X C R I+735 \mathrm{C}$ (histidine) variant was connected to the higher mastitis susceptibility when analysed within the haplotype. It should be mentioned, however, that the subclinical mastitis study was done on 66 animals with some of the haplotypes found only in 3 or 7 animals, which means that the result require confirmation in a larger group.

\section{Conclusions}

Test day SCC in Polish Holsteins was associated with the $C X C R 1$ genotype and $C X C R 1+735 /+472$ haplotype. The GG genotype of $C X C R 1+472$ and $C G$ genotype of $C X C R 1+735$ were the most favourable regarding low SCC. No association between $S$. aureus mastitis susceptibility and $C X C R 1$ genotype was observed in the studied herd. The study results need verification with the use of EBV to confirm the potential of $C X C R 1+472$ polymorphism as a marker of mastitis susceptibility in dairy cows.

The authors declare no conflict of interest.

This work was supported by Polish National Centre of Science grant no 2011/01/N/NZ9/00567.

\section{References}

1. Malinowski E, Lassa H, Kłosowska A, et al. (2009): Atypical Staphylococcus aureus as an aetiological agent of mastitis in cows. Bull Vet Inst Pulawy 53: 383-387.

2. Lutzow YC, Donaldson L, Gray CP, et al. (2008): Identification of immune genes and proteins involved in the response of bovine mammary tissue to Staphylococcus aureus infection. BMC Vet Res 4: 18.

3. Kościuczuk EM, Lisowski P, Jarczak J, et al. (2014): Expression patterns of $\beta$-defensin and cathelicidin genes in parenchyma of bovine mammary gland infected with coagulase-positive or coagulase-negative Staphylococci. BMC Vet Res 10: 246.

4. von Köckritz-Blickwede M, Rohde M, Oehmcke S, et al. (2008): Immunological mechanism underlying the genetic predisposition to severe Staphylococcus aureus infection in the mouse model. Am J Pathol 173: 1657-1668.

5. Sender G, Korwin-Kossakowska A, Stepinska U (2003): Utilizing genetic markers for mastitis resistance. Med Weter 59: 853-856.

6. Artifoni L, Negrisolo S, Montini G, et al. (2007): Interleukin-8 and CXCR1 receptor functional polymorphisms and susceptibility to acute pyelonephritis. J Urol 177: 1102-1106.

7. Alluwaimi AM (2005): IL8 transcriptional activity in S. aureus mastitis. Int J Diary Sci 1: 18-20.

8. Youngerman SM, Saxton AM, Oliver SP, Pighetti GM (2004): Association of CXCR2 polymorphisms with subclinical and clinical mastitis in dairy cattle. J Diary Sci 87: 2442-2448.

9. Pighetti GM, Kojima CJ, Wojakiewicz L, Rambeaud M (2012): The bovine CXCR1 gene is highly polymorphic. Vet Immunol Immunopathol 145: 464-470.

10.Zhou L, Wang HM, Ju ZH, et al. (2013): Association of novel single nucleotide polymorphisms of the CXCR1 gene with the milk performance traits of Chinese native cattle. Genet Mol Res 12: 2725-2739.

11. Goertz I, Baes C, Weimann C, et al. (2009): Association between single nucleotide polymorphisms in the CXCR1 gene and somatic cell score in Holstein dairy cattle. J Dairy Sci 92: 4018-4022.

12. Grosse WM, Kappes SM, Laegreid WW, et al. (1999): Single nucleotide polymorphism (SNP) discovery and linkage mapping of bovine cytokine genes. Mamm Genome 10: 10621069.

13. Rambeaud M, Pighetti GM (2005): Impaired neutrophil migration associated with specific bovine CXCR2 genotypes. Infect Immun 73: 4955-4959.

14.Pighetti GM, Rambeaud M (2006): Genome conservation between the bovine and human Interleukin-8 receptor complex: improper annotation of bovine Interleukin-8 receptor B identified. Vet Immunol Immunopathol 114: 335-340.

15.Park SH, Das BB, Casagrande F, et al. (2012): Structure of the chemokine receptor CXCR1 in phospholipid bilayers. Nature 491: 779-783.

16. Russell CD (2012): Single Nucleotide Polymorphisms in Bovine Chemokine and Toll-Like Receptors; Impacts on Disease Susceptibility and Productivity in Dairy Cattle. Doctor of Philosophy Thesis, Chapter 6. University of Nottingham.

17. Kanai N, Fujii T, Saito K, Tokoyama T (1994): Rapid and Simple method for preparation of genome DNA from easily obtained clotted blond. J Clin Pathol 47: 1043-1044.

18. Ali A, Shook GE (1980): An optimum transformation for somatic cell concentration in milk. J Dairy Sci 63: 487-490.

19.Zhang CL, Wang Y, Chen H, et al. (2012): The chemokine receptor 1 gene polymorphism and its association with Somatic Cell Score and milk production traits in dairy cattle. Anim Sci Pap Rep 30: 25-33.

20. Galvăo KN, Pighetti GM, Cheong SH, et al. (2011): Association between interleukin- 8 receptor- $\alpha$ (CXCR1) polymorphism and disease incidence, production, reproduction, and survival in Holstein cows. J Dairy Sci 94: 2083-2091. 
21.Leyva-Baca I, Schenkel F, Sharma BS, et al. (2007): Identification of single nucleotide polymorphisms in the bovine CCL2, IL8, CCR2 and IL8RA genes and their association with health and production in Canadian Holsteins. Anim Genet 38: 198-202.

22.Elliot AA (2010): Identifying Mechanisms Associated with Innate Immunity in Cows Genetically Susceptible to Mastitis. Doctor of Philosophy Thesis, University of Tennessee.

23. Crisp OJ (2014): Genetic Resistance to Staphylococcus aureus Mastitis Associated with Bovine CXCR1. Honors Thesis Projects, University of Tennessee. 